Artur-Axel Wandtke, Claudia Ohst (Hrsg.)

Praxishandbuch Medienrecht

De Gruyter Praxishandbuch 



\section{Praxishandbuch Medienrecht}

\section{Band 1: Europäisches Medienrecht und Durchsetzung des geistigen Eigentums}

\section{3., neu bearbeitete Auflage}

Herausgegeben von

Prof. Dr. Artur-Axel Wandtke, em. o. Professor an der Humboldt-Universität zu Berlin und Dr. Claudia Ohst, Fachanwältin für Informationstechnologierecht, Lehrbeauftragte der Humboldt-Universität zu Berlin

\section{Bearbeitet von}

Rechtsanwalt Professor Dr. Oliver Castendyk, MSc. (LSE), Berlin;

Rechtsanwalt Dr. Soenke Fock, LL.M., Fachanwalt für gewerblichen Rechtsschutz,

Wildanger Kehrwald Graf v. Schwerin \& Partner mbB Rechtsanwälte, Düsseldorf;

Rechtsanwältin Andrea Kyre, LL.M., General Counsel bei Visual Meta GmbH, ein Unternehmen der Axel Springer SE Digital, Berlin;

Rechtsanwalt Professor Dr. Ferdinand Melichar, Grub Brugger, München;

Professor Dr. Artur-Axel Wandtke, em. o. Professor der Humboldt-Universität zu Berlin;

Rechtsanwalt Dr. Marcus von Welser, LL.M., München, Fachanwalt für gewerblichen

Rechtsschutz, Lehrbeauftragter an der Humboldt-Universität zu Berlin

\section{DE GRUYTER}


Zitiervorschlag: Wandtke/Ohst/Bearbeiter, Praxishandbuch Medienrecht, Bd 1, Kap 1 Rn 23.

ISBN 978-3-11-031388-8

e-ISBN 978-3-11-031411-3

\section{Bibliografische Information der Deutschen Nationalbibliothek}

Die Deutsche Nationalbibliothek verzeichnet diese Publikation in der Deutschen Nationalbibliografie; detaillierte bibliografische Daten sind im Internet über http://dnb.d-nb.de abrufbar.

(C) 2014 Walter de Gruyter GmbH, Berlin/Boston

Datenkonvertierung/Satz: jürgen ullrich typosatz, 86720 Nördlingen

Druck: CPI books GmbH, Leck

@ Gedruckt auf säurefreiem Papier

Printed in Germany

www.degruyter.com 